\title{
Effects of different levels of protein-to-energy ratios on nutrient digestibility and digestive enzyme activity in Leiothrix luteal
}

\author{
Yuan Shi-bin*, Zhou Cai-quan* and Qi Sai-fei \\ Institute of Rare Animals and Plants, College of Life Sciences, China West Normal University, Nanchong, Key \\ Laboratory of Southwest China Wildlife Resources Conservation (Ministry of Education) Nanchong, Sichuan, 637002, \\ People's Republic of China. \\ Accepted 24 August, 2012
}

\begin{abstract}
Effects of different levels of protein-to-energy ratios (PER) on nutrient utilization, digestive organs index and digestive enzymes activities in Leiothrix luteal were investigated in this research. It was found that different PER feedstuff had no significant effects on the utilization of dry matter (DM), calcium (Ca) and total phosphorus (TP). With the improvement of the PER, average daily feed intake (ADFI) gradually increased, the apparent utilization rate of energy and fat gradually improved, while the apparent utilization rate of crude protein increased at first and then decreased. Development of digestive organs of $L$. luteal was affected by the level of dietary PER, with the increase in PER, the digestive organ indices of muscular stomach, duodenum, jejunoileum and rectum exhibited a downward trend, the main influencing factors were the level of metabolizable energy in diets. With the intestinal tract moving backward, the relative activity of proteases gradually reduced, manifesting as pancreas $>$ duodenum $>$ jejunoileum. The relative activity of carbohydrate digestion enzymes gradually increased as the intestinal tract moved backward. With the improvement of PER, the relative activity of lipase gradually decreased in pancreas, duodenum, and jejunoileum. L. luteal possessed a strong ability to digest crude fiber and total phosphorus; the reason might be closely related to the types and quantities of intestinal flora, which was affected by the feeding habits of this bird. By comprehensively considering the nutrient utilization, digestive organ indices and digestive enzymes activities, the formula of PER II was more appropriate for nutritional needs of $L$. luteal in captivity.
\end{abstract}

Key words: Leiothrix luteal, protein-to-energy ratios, nutrients, digestion and utilization, enzyme activities.

\section{INTRODUCTION}

The Leiothrix luteal belonging to the Timaliidae family (Passeriformes), widely distributed in China's southern provinces, was also found in northern Vietnam and the western and northern parts of Myanmar (Zheng, 2005). The bird is a regional common species or dominant species and plays an important role in forest ecosystems. Because of its small and exquisite body shape, mildly sweet sound and gorgeous colors, it is welcomed by the majority of aviculturist at home and abroad (Ma et al.,

*Corresponding authors. E-mail: yshibin@ $@$ sina.com,
drcqzhou1@163.com.

2000). In recent years, with the trade of $L$. luteal rising, the hunting pressure dramatically increased and the quantity of wild L. luteal has drastically declined (Guo et al., 2009). The L. luteal was listed in Appendix II by the Convention on International Trade in Endangered Species of Wild Fauna and Flora (CITES) in June 20, 1997 (Harare, Zimbabwe) (Fan, 1997). It was listed in State protection, beneficial or of important economic or scientific value of terrestrial wildlife List (issued by State Forestry Administration) in August 1, 2000. It was listed in International birds Redbook by The World Conservation Union in 2009. Artificial breeding and domestication is one of the important protection measures for ex situ 
conservation of $L$. luteal. Currently, the research related to $L$. luteal has focused on the number of distribution, population status, habitat selection, foraging ecology (Ma et al., 2010; Liu et al., 1989), while domestication and breeding has seldom been reported. In sporadic reports of $L$. luteal in captivity, there is considerable arbitrariness in the choice of the feed and feeding technology, it is difficult to achieve intensive farming and the establishment of artificial populations to meet the domestic and external demand (Guo et al., 2009; Sun et al., 1996). Based on animal nutritional research, effects of different level of protein-to-energy ratios (PER) on nutrient utilization, digestive organs index and digestive enzymes activities in L. luteal were investigated in this research, the theoretical basis for feeding management of $L$. luteal in captivity was initially established, laying the foundation for further study of standard nutrient requirement of $L$. luteal and ex situ conservation.

\section{MATERIALS AND METHODS}

\section{Animals feeding management}

The experiment was performed in Institute of rare animals and plants at the College of Life Sciences of China West Normal University (Nanchong City, Sichuan Province). During the preparation period, the birds were housed in large wire cages $(4.8 \times$ $2.1 \times 2.4 \mathrm{~m}$ ), the perch was built with branches, the cages was decorated with the Cinnamomum japonicum and Rhapis gracilis and other potted plants, and hay flakes were laid on the floor near the window, such as Bermuda grass, fibrous roots of Ficus microcarpa and palm silk to amuse the birds. Food containers, water boxes and tub were placed on the open space; the depth of tub was appropriate to prevent the birds drowning. During the course of the experiment, 40 female birds ( $q$, average $\mathrm{BW}=17.95$ $\pm 0.11 \mathrm{~g}$ ) were chosen from large wire cages and randomly divided into four treatment groups; Each treatment group contained five replicates, and each replicates contained two birds. The birds were housed in small wire cages $(0.69 \times 0.41 \times 0.32 \mathrm{~m})$. The birds were housed at temperature of 25 to $30^{\circ} \mathrm{C}$, humidity of $65 \%$, and had free access to water and fed regularly.

\section{Experimental diets}

The basal diet consisted of cereal seed mixture, soybean meal and animal protein mixture. The cereal seed mixture consisted of maize, sorghum, broken rice, wheat bran and flour with proportion of 100: 53: 80: 53: 67 . The animal protein mixture was made from fish meal, shrimp, silkworm with proportion of 100: 100: 83. The preparation of diets was based on the nutrient requirements of daily diet of the Americas quail for U.S. NRC (1994) and feed composition and nutritional value of table of China (19th, 2008) (Chan et al., 2005). The composition and nutritional content of the experimental diets is listed in Table 1. The feed was full of broken material.

\section{Index measurement and methods}

The pre-feeding period lasted one week and the trial period was eight weeks. Metabolism trials were perfomed in the fifth week of the formal experiment. The birds were slaughtered to get samples 1 $h$ after feeding in the next morning at the end of the formal experiment.

\section{Nutrient utilization}

Moisture, dry matter, crude protein, crude fat, calcium, phosphorus and energy of feed and feces were measured according to Feed Experiments Guidance (Wang and Wang, 2006). The crude protein was measured using the Kjeldahl nitrogen analyzer (HD 4020, China Jinan Hanon Intrument Co., Ltd.). Fat content was determined by fat analyzer (SOX 416, China Jinan Hanon Instrument Co., Ltd.). Energy was measured according to the operating manual using oxygen bomb calorimeter (PARR 6400, Parr Company). Calcium was measured using complexometric titration, with reference to GB/T 6436-2002 of EDTA. Phosphorus was measured using spectrophotometry, according to GB/T 64372002.

Apparent utilization of nutrients $(\%)=[($ The total intake of a nutrient - total excretion of a nutrient) / The total intake of a nutrient] $\times 100$.

\section{Digestive organs index}

One bird was randomly selected from each replicate, weighed and killed by decapitation under light anaesthesia with diethyl ether. After the separation of the liver, pancreas, glandular stomach, muscular stomach, duodenum, jejunoileum and rectum, adherent fat and contents were removed and timely weighed. Digestive organ indices were expressed as the relative weight of the digestive organs to the body weight ratio (mg/g BW).

\section{Enzyme activities of digestive organs}

The duodenum, jejunoileum, cecum, and rectum were fractional ligated, rapidly removed, weighed, and quick-frozen in liquid nitrogen tank. The liver, and pancreas were extracted, weighed, sampled and homogenized at low temperature and the homogenate was diluted to a constant volume of $50 \mathrm{ml}$, and centrifuged $(3000$ $\mathrm{r} / \mathrm{min}$ ) at $4^{\circ} \mathrm{C}$. The supernatant was packed and quickly frozen in liquid nitrogen, and then transferred to a $-80^{\circ} \mathrm{C}$ refrigerator for futher use.

The trypsin, protease, lipase, amylase, lactase and cellulase activity of the contents of duodenum, and jejunoileum was determined. Pancreatic proteases, protease, lipase, and lactase activity in the pancreas and lipase activity in the liver was determined. The trypsin activity was determined with N-Crafts acyl$\mathrm{L}$-arginine ethyl estermethod (BAEE). The protease was determined with benzoyl-L-tyrosine ethyl ester method (BTEE). The lipase activity was determined with alkali titration method. The amylase activity was determined with iodine binding assay. The lactase activity was determined with o-nitrophenyl-beta-D-half lactose pyran glucoside (DNPG) method. The cellulase activity was determined with sodium carboxymethylcellulose method. The detailed protocol was according to methods for measuring enzyme activities (Stellmacher et al., 1992).

Enzyme relative activity $=$ Enzyme activity units / weight of sample

Total enzyme activity $=$ Enzyme relative activity $\times$ contents weight of intestinal canal or the weight of pancreas or liver.

\section{Statistical analysis}

The results were presented as mean \pm standard. SPSS 11.0 
Table 1. The diet formula and nutrition composition of Leiothrix luteal in each treatment group.

\begin{tabular}{lcccc}
\hline Ingredient (\%) & I & II & III & IV \\
\hline Cereal seed mixture & 50.4 & 53 & 55.2 & 56.7 \\
Soybean & 18.0 & 17.3 & 16.8 & 16.1 \\
Animal protein mixture & 17.0 & 17.0 & 17.0 & 17.0 \\
Oil and fat & 4.0 & 3.0 & 2.0 & 1.0 \\
Ricebran & 8.80 & 7.90 & 7.20 & 7.40 \\
CaCO $_{3}$ & 0.60 & 0.60 & 0.60 & 0.60 \\
Salt & 0.20 & 0.20 & 0.20 & 0.20 \\
$1 \%{ }^{\oplus}$ Premix & 1.00 & 1.00 & 1.00 & 1.00 \\
Total & 100 & 100 & 100 & 100 \\
& & & & \\
Nutrient level & & & & \\
PER (g/ MJ) & 15.61 & 16.25 & 16.74 & 17.33 \\
GE (MJ/ kg) & 13.54 & 13.00 & 12.62 & 12.19 \\
CP (\%) & 21.13 & 21.13 & 21.13 & 21.13 \\
EE (\%) & 6.32 & 6.32 & 6.32 & 6.32 \\
CF (\%) & 5.50 & 5.62 & 5.65 & 5.74 \\
Ca (\%) & 0.68 & 0.68 & 0.68 & 0.68 \\
TP (\%) & 0.45 & 0.45 & 0.45 & 0.45 \\
Salt (\%) & 0.35 & 0.35 & 0.35 & 0.35 \\
\hline
\end{tabular}

$1 \%$ premix provided per kilogram of complete feed: $12 \mathrm{mg}$ retinol, $2.5 \mathrm{mg}$ pyridoxine, $0.02 \mathrm{mg}$ cholecalciferol, $20 \mathrm{mg}$ tocopherol, $50 \mathrm{mg}$ nicotinic acid, $2 \mathrm{mg}$ menadione, $12 \mathrm{mg}$ pantothenic acid, $12 \mathrm{ug}$ cyanocobalamin, $6 \mathrm{mg}$ riboflavin, $0.30 \mathrm{mg}$ biotin, $1.10 \mathrm{mg}$ folic acid, $1500 \mathrm{mg}$ choline, 100 $\mathrm{mg} \mathrm{Fe}, 25 \mathrm{mg} \mathrm{Zn,} 6 \mathrm{mg} \mathrm{Cu}, 90 \mathrm{mg} \mathrm{Mn}, 0.2 \mathrm{mg} \mathrm{Se}, 0.3 \mathrm{mg} \mathrm{I}, 0.05 \mathrm{mg} \mathrm{Mg}$.

Table 2. Effects of different level of PER feedstuff on apparent utilization of nutrients of Leiothrix luteal.

\begin{tabular}{lcccc}
\hline \multirow{2}{*}{ Index } & \multicolumn{3}{c}{ Group } \\
\cline { 2 - 5 } & I & II & III & IV \\
\hline ADFI (g) & $9.11 \pm 1.66^{\mathrm{A}}$ & $10.57 \pm 2.51^{\mathrm{A}}$ & $13.57 \pm 2.11^{\mathrm{B}}$ & $14.10 \pm 1.96^{\mathrm{B}}$ \\
DM & $54.46 \pm 2.55$ & $53.68 \pm 3.41$ & $53.31 \pm 4.57$ & $49.56 \pm 2.34$ \\
Crude protein (CP) & $43.55 \pm 2.63^{\mathrm{ABb}}$ & $46.56 \pm 4.23^{\mathrm{Aa}}$ & $40.57 \pm 2.99^{\mathrm{BC}}$ & $39.56 \pm 2.87^{\mathrm{BC}}$ \\
Crude fat (CF) & $46.99 \pm 3.77^{\mathrm{A}}$ & $50.76 \pm 4.12^{\mathrm{B}}$ & $53.90 \pm 2.56^{\mathrm{C}}$ & $57.23 \pm 3.30^{\mathrm{D}}$ \\
Ca & $20.45 \pm 1.56$ & $19.57 \pm 2.33$ & $21.33 \pm 3.23$ & $18.77 \pm 2.19$ \\
Total phosphorous (TP) & $69.80 \pm 0.99$ & $67.56 \pm 1.77$ & $72.33 \pm 2.56$ & $71.55 \pm 2.31$ \\
Energy & $50.11 \pm 4.55^{\mathrm{A}}$ & $53.45 \pm 2.99^{\mathrm{B}}$ & $55.43 \pm 2.56^{\mathrm{B}}$ & $62.33 \pm 1.99^{\mathrm{C}}$ \\
\hline
\end{tabular}

software package was employed to analyze the data, and multiple comparisons were performed with Duncan's test.

\section{RESULTS}

\section{Effect of different level of PER feedstuff on apparent utilization of nutrients of Leiothrix luteal}

The effect of different level of PER feedstuff on apparent utilization of nutrients of $L$. luteal was summarized (Table
2). For each treatment group, the utilization of $\mathrm{DM}, \mathrm{Ca}$, and TP showed no significant differences. With the improvement of the PER, average daily feed intake (ADFI) gradually increased, and the apparent utilization rate of energy and fat gradually improved. The apparent utilization rate of crude protein increased at first and then decreased.

PERII exhibited the highest apparent utilization rate of crude protein among the four treatment group; It was higher than that of PER I $(p<0.05)$ and significantly higher than that of PER III and PER IV $(p<0.01)$. 
Table 3. Weight of digestive organs of Leiothrix luteal.

\begin{tabular}{cccccccc}
\hline Group & Liver & Pancreas & Glandular & Muscular stomach & Duodenum & Jejunoileum & Rectum \\
\hline I & $0.572 \pm 0.013$ & $0.093 \pm 0.0543$ & $0.072 \pm 0.023$ & $0.731 \pm 0.036^{\mathrm{A}}$ & $0.363 \pm 0.015^{\mathrm{a}}$ & $0.724 \pm 0.035^{\mathrm{A}}$ & $0.092 \pm 0.011^{\mathrm{A}}$ \\
II & $0.573 \pm 0.024$ & $0.096 \pm 0.061$ & $0.068 \pm 0.054$ & $0.712 \pm 0.02 \mathrm{~A}^{\mathrm{AB}}$ & $0.359 \pm 0.021^{\mathrm{ab}}$ & $0.699 \pm 0.027^{\mathrm{B}}$ & $0.087 \pm 0.024^{\mathrm{A}}$ \\
III & $0.565 \pm 0.067$ & $0.089 \pm 0.057$ & $0.082 \pm 0.036$ & $0.696 \pm 0.056^{\mathrm{AB}}$ & $0.342 \pm 0.013^{\mathrm{b}}$ & $0.685 \pm 0.038^{\mathrm{B}}$ & $0.076 \pm 0.015^{\mathrm{B}}$ \\
IV & $0.580 \pm 0.053$ & $0.087 \pm 0.481$ & $0.079 \pm 0.044$ & $0.662 \pm 0.043^{\mathrm{B}}$ & $0.335 \pm 0.014^{\mathrm{b}}$ & $0.669 \pm 0.039^{\mathrm{C}}$ & $0.073 \pm 0.014^{\mathrm{B}}$ \\
\hline
\end{tabular}

\section{Effect of different level of PER feedstuff on weight of digestive organs and digestive organ indices of $L$. luteal}

The effect of different level of PER feedstuff on weight of digestive organs was summarized (Table 3). For each treatment group, no significant weight differences of liver, pancreas, and proventriculus were found $(p>0.05)$; The weight difference of duodenum was significant $(p<0.05)$ and weight differences of muscular stomach, jejunoileum, and rectum were significant $(p<0.01)$. With the increase in PER level, the weight of muscular stomach, duodenum, jejunoileum, and rectum exhibited downward trend.

The effect of different level PER feedstuff on digestive organ indices of $L$. luteal is summarized in Table 4 . For each treatment group, the digestive organ indices of liver, muscle, stomach and duodenum showed no significant difference. With the improvement of PER, the digestive organ indices of pancreas initially increased and then decreased, and the highest digestive organ indices was found in PER II, which was significantly higher than that of PER III and PER IV $(p<0.05)$. The digestive organ indices of glandular stomach reached the maximum value which was significantly higher than that of PER I and PER II. With the improvement of PER, the digestive organ indices of jejunoileum and rectum decreased gradually, which decreased significantly from PER III ( $p<$ $0.01)$ and PER IV $(p<0.01)$.

\section{Effects of different level of PER on digestive enzymes activities in $L$. Iuteal}

\section{Determination of protease activities}

The effect of different level PER feedstuff on protease activities of $L$. luteal is summarized in Table 5 . For each treatment group, with the improvement of PER, the relative activity of trypsin and total chymotrypsin in jejunoileum did not change significantly $(p>0.05)$, the activities of trypsin and total chymotrypsin in other organs differed $(p<0.05)$ or were significantly different $(p<$ 0.01). With the PER of diets elevated, the activities of trypsin and chymotrypsin initially increased and then decreased, and enzyme activities reached the maximum value in PERII. With the intestinal tract moving backward, the total activities of trypsin and chymotrypsin gradually decreased, exhibiting the trend pancreas $>$ duodenum $>$ jejunoileum.

\section{Comparison of lipase activities}

The effect of different level of PER feedstuff on lipase of the digestive organs and tract is summarized in Table 6 . With the improvement of PER, the relative activity and total activity of lipase in liver, the total activity of lipase in pancreas and jejunoileum did not change significantly, and the relative activity of lipase in pancreas, duodenum and jejunoileum, totalactivity of lipase in duodenum gradually decreased. For each treatment group, the relative activity and total activity of lipase in jejunoileum was higher than that in jejunoileum.

\section{Comparison of carbohydrate digestion enzymes activities}

The effect of different level of PER feedstuff on the relative activity and total activity of amylase, lactase, and cellulase in digestive and tract was summarized (Table 7). With the improvement of PER, the relative activity of amylase in duodenum and jejunoileum initially increased and then decreased. The highest amylase activity was found in PERII and the relative activity of amylase in jejunoileum was significantly higher than that of PER IV $(p<0.05)$. The total activity of lactase decreased gradually with elevated level of PER; The lactase activities in each treatment group varied significantly $(p<$ 0.05 ), and the total activities of lactase in PER I and PER II (duodenum) were significantly higher than that of PER IV $(p<0.05)$. The activity of cellulase in duodenum and jejunoileum gradually increased with the PER level elevated. When the intestinal tract moved backward, the carbohydrate digestion enzyme activities increased; The activity of amylase and cellulase exhibited the trend duodenum < jejunoileum, and the lactase activity exhibited the trend pancreas $<$ duodenum $<$ jejunoileum.

\section{DISCUSSION}

Nutrient utilization rate refers to the percentage of 
Table 4. Digestive organ indices of Leiothrix luteal.

\begin{tabular}{cccccccc}
\hline Group & Liver & Pancreas & Glandular & Muscular stomach & Duodenum & Jejunoileum & Rectum \\
\hline I & $31.85 \pm 0.31$ & $5.18 \pm 0.08^{\mathrm{ab}}$ & $4.01 \pm 0.22^{\mathrm{B}}$ & $40.70 \pm 0.67$ & $20.21 \pm 0.31$ & $40.31 \pm 0.56^{\mathrm{a}}$ & $5.12 \pm 0.0 .31^{\mathrm{Aa}}$ \\
II & $31.45 \pm 0.22$ & $5.27 \pm 0.06^{\mathrm{a}}$ & $3.73 \pm 0.34^{\mathrm{B}}$ & $39.08 \pm 0.52$ & $19.70 \pm 0.32$ & $38.36 \pm 0.47^{\mathrm{ab}}$ & $4.77 \pm 0.23^{\mathrm{Ab}}$ \\
III & $31.46 \pm 0.25$ & $4.96 \pm 0.09^{\mathrm{b}}$ & $4.57 \pm 0.29^{\mathrm{A}}$ & $38.75 \pm 0.65$ & $19.04 \pm 0.29$ & $38.14 \pm 0.53^{\mathrm{ab}}$ & $4.23 \pm 0.44^{\mathrm{BC}}$ \\
IV & $32.81 \pm 0.36$ & $4.92 \pm 0.14^{\mathrm{b}}$ & $4.47 \pm 0.44^{\mathrm{A}}$ & $37.44 \pm 0.54$ & $18.95 \pm 0.40$ & $37.84 \pm 0.66^{\mathrm{b}}$ & $4.13 \pm 0.39^{\mathrm{Bc}}$ \\
\hline
\end{tabular}

Table 5. Determination of digestive enzymes activities.

\begin{tabular}{|c|c|c|c|c|c|}
\hline \multirow{2}{*}{ Index } & \multirow{2}{*}{ Organ } & \multicolumn{4}{|c|}{ Group } \\
\hline & & I & II & III & IV \\
\hline \multicolumn{6}{|l|}{ Trypsin } \\
\hline \multirow{3}{*}{$\begin{array}{l}\text { Relative } \\
\text { activity }\end{array}$} & Pancreas (U/g) & $26194.91 \pm 427.03^{B}$ & $29650.88 \pm 1124.47^{A}$ & $25323.78 \pm 1414.56^{\mathrm{A}}$ & $19870.45 \pm 987.56^{C}$ \\
\hline & Duodenum (U/g) & $4940.97 \pm 178.76^{\mathrm{B}}$ & $5392.78 \pm 152.23^{\mathrm{A}}$ & $4963.45 \pm 276.41^{\mathrm{B}}$ & $4753.50 \pm 332.13^{B}$ \\
\hline & Jejunoileum $(\mathrm{U} / \mathrm{g})$ & $1990.37 \pm 36.68$ & $2149.77 \pm 96.20$ & $2045.63 \pm 87.34$ & $1987.66 \pm 65.43$ \\
\hline \multirow{3}{*}{ Total } & Pancreas (U) & $2457.54 \pm 38.43^{\mathrm{BC}}$ & $2965.09 \pm 112.45^{\mathrm{Aa}}$ & $2733.34 \pm 78.23^{\mathrm{Ab}}$ & $2654.56 \pm 65.34^{\mathrm{Ab}}$ \\
\hline & Duodenum (U) & $1507.57 \pm 67.93^{\mathrm{B}}$ & $1844.33 \pm 52.06^{A}$ & $1799.35 \pm 55.32^{\mathrm{AB}}$ & $1653.22 \pm 52.43^{B}$ \\
\hline & Jejunoileum (U) & $1173.85 \pm 29.27$ & $1375.85 \pm 74.37$ & $1259.66 \pm 73.20$ & $1202.45 \pm 43.55$ \\
\hline \multicolumn{6}{|c|}{ Chymotrypsin } \\
\hline \multirow{3}{*}{$\begin{array}{l}\text { Relative } \\
\text { activity }\end{array}$} & Pancreas (U/g) & $49.98 \pm 1.33^{\mathrm{ab}}$ & $53.83 \pm 1.47^{\mathrm{a}}$ & $47.56 \pm 2.01^{\mathrm{ab}}$ & $46.76 \pm 1.98^{\mathrm{c}}$ \\
\hline & Duodenum (U/g) & $1.42 \pm 0.06^{\mathrm{a}}$ & $1.55 \pm 0.13^{\mathrm{a}}$ & $1.46 \pm 0.22^{\mathrm{a}}$ & $1.33 \pm 0.16^{b}$ \\
\hline & Jejunoileum $(\mathrm{U} / \mathrm{g})$ & $0.69 \pm 0.03^{\mathrm{BC}}$ & $0.82 \pm 0.02^{\mathrm{Aa}}$ & $0.74 \pm 0.04^{\mathrm{ABb}}$ & $0.67 \pm 0.03^{\mathrm{Bc}}$ \\
\hline \multirow{3}{*}{ Total } & Pancreas $(U)$ & $3.98 \pm 0.12^{\mathrm{B}}$ & $5.39 \pm 0.15^{\mathrm{A}}$ & $4.57 \pm 0.15^{\mathrm{AB}}$ & $3.43 \pm 0.17^{B}$ \\
\hline & Duodenum (U) & $0.43 \pm 0.02^{\mathrm{bc}}$ & $0.53 \pm 0.04^{\mathrm{a}}$ & $0.47 \pm 0.03^{\mathrm{ab}}$ & $0.39 \pm 0.01^{c}$ \\
\hline & Jejunoileum (U) & $0.47 \pm 0.02$ & $0.52 \pm 0.01$ & $0.50 \pm 0.02$ & $0.49 \pm 0.03$ \\
\hline
\end{tabular}

Table 6. Comparison of carbohydrate digestion enzymes (lipase) activities in Leiothrix luteal.

\begin{tabular}{|c|c|c|c|c|c|}
\hline \multirow{2}{*}{ Index } & \multirow{2}{*}{ Organ } & \multicolumn{4}{|c|}{ Group } \\
\hline & & I & II & III & IV \\
\hline \multirow{4}{*}{$\begin{array}{c}\text { Relative } \\
\text { activity }\end{array}$} & Liver $(\mathrm{U} / \mathrm{g})$ & $635.31 \pm 13.28$ & $643.27 \pm 19.87$ & $654.32 \pm 18.24$ & $637.38 \pm 45.32$ \\
\hline & Pancreas $(\mathrm{U} / \mathrm{g})$ & $1369.50 \pm 25.36^{\mathrm{A}}$ & $1295.09 \pm 73.08^{\mathrm{AB}}$ & $1245.23 \pm 33.32^{\mathrm{AB}}$ & $1096.73 \pm 56.24^{\mathrm{B}}$ \\
\hline & Duodenum (U/g) & $576.17 \pm 17.06^{\mathrm{a}}$ & $557.85 \pm 26.12^{\mathrm{a}}$ & $544.12 \pm 14.56^{\mathrm{ab}}$ & $522.43 \pm 27.65^{\mathrm{b}}$ \\
\hline & Jejunoileum $(\mathrm{U} / \mathrm{g})$ & $1185.19 \pm 36.44^{A}$ & $1066.65 \pm 54.35^{\mathrm{AB}}$ & $954.32 \pm 43.24^{\mathrm{B}}$ & $903.25 \pm 56.43^{\mathrm{B}}$ \\
\hline \multirow{4}{*}{ Total } & Liver (U) & $324.27 \pm 7.36$ & $342.22 \pm 10.57$ & $335.14 \pm 27.56$ & $298.17 \pm 16.43$ \\
\hline & Pancreas (U) & $105.26 \pm 2.28$ & $109.51 \pm 7.31$ & $102.35 \pm 11.23$ & $110.45 \pm 9.81$ \\
\hline & Duodenum (U) & $446.95 \pm 6.48^{\mathrm{a}}$ & $395.99 \pm 19.19^{b}$ & $377.23 \pm 22.54^{b}$ & $315.66 \pm 12.44^{c}$ \\
\hline & Jejunoileum (U) & $945.78 \pm 29.08$ & $874.66 \pm 34.78$ & $882.33 \pm 27.00$ & $925.29 \pm 20.25$ \\
\hline
\end{tabular}

nutrients accounting for ingestion of feed nutrients taken preparation of balanced diet of caged birds, which can reflect the utilization of feedstuff of birds. An important indicator of the nutritional requirements of caged birds. Factors affecting the nutrient utilization rate are mainly the content and proportion of nutrients in feedstuff, structure and morphology of digestive tract of birds. This study found that nutrient utilization rate of $L$. luteal was far lower than that for poultry. Based on the ratio of intestinal tract length to body length on the L. luteal and a comparative study of galliformes and falconiformes, the ratio of intestinal tract length to body length on the $L$. luteal was far less than the galliformes and falconiformes. The $L$. luteal manifested frequent intake and defecation, 
Table 7. Comparison of carbohydrate digestion enzymes activities in Leiothrix luteal.

\begin{tabular}{|c|c|c|c|c|c|}
\hline \multirow{2}{*}{ Index } & \multirow{2}{*}{ Organ } & \multicolumn{4}{|c|}{ Group } \\
\hline & & I & II & III & IV \\
\hline \multicolumn{6}{|l|}{ Amylase } \\
\hline \multirow{2}{*}{ Relative activity } & Duodenum (U/g) & $18.32 \pm 0.91$ & $19.18 \pm 0.72$ & $17.56 \pm 0.87$ & $17.23 \pm 0.99$ \\
\hline & Jejunoileum (U/g) & $32.60 \pm 1.04^{a}$ & $35.15 \pm 1.23^{\mathrm{a}}$ & $29.65 \pm 4.50^{\mathrm{ab}}$ & $28.43 \pm 2.30^{b}$ \\
\hline \multirow[b]{2}{*}{ Total } & Duodenum (U) & $15.42 \pm 0.73$ & $15.36 \pm 0.46$ & $13.25 \pm 1.23$ & $14.57 \pm 0.55$ \\
\hline & Jejunoileum (U) & $13.15 \pm 0.39^{b}$ & $18.60 \pm 0.42^{\mathrm{a}}$ & $15.15 \pm 0.54^{b}$ & $14.25 \pm 0.35^{\mathrm{b}}$ \\
\hline \multicolumn{6}{|l|}{ Lactase } \\
\hline \multirow{3}{*}{ Relative activity } & Pancreas (U/g) & $0.64 \pm 0.03$ & $0.60 \pm 0.02$ & $0.59 \pm 0.01$ & $0.55 \pm 0.03$ \\
\hline & Duodenum $(\mathrm{U} / \mathrm{g})$ & $0.73 \pm 0.02$ & $0.70 \pm 0.05$ & $0.69 \pm 0.04$ & $0.67 \pm 0.01$ \\
\hline & Jejunoileum $(\mathrm{U} / \mathrm{g})$ & $1.22 \pm 0.03$ & $1.14 \pm 0.05$ & $1.07 \pm 0.03$ & $1.15 \pm 0.02$ \\
\hline \multirow{3}{*}{ Total } & Pancreas (U) & $0.51 \pm 0.02^{\mathrm{a}}$ & $0.38 \pm 0.01^{b}$ & $0.33 \pm 0.03^{b}$ & $0.17 \pm 0.02^{c}$ \\
\hline & Duodenum (U) & $0.28 \pm 0.01^{\mathrm{a}}$ & $0.24 \pm 0.02^{\mathrm{a}}$ & $0.19 \pm 0.02^{\mathrm{ab}}$ & $0.11 \pm 0.01^{b}$ \\
\hline & Jejunoileum $(U)$ & $0.11 \pm 0.00$ & $0.11 \pm 0.00$ & $0.08 \pm 0.01$ & $0.13 \pm 0.02$ \\
\hline \multicolumn{6}{|l|}{ Cellulase } \\
\hline \multirow{2}{*}{ Relative activity } & Duodenum (U/g) & $17.02 \pm 0.49^{a}$ & $19.47 \pm 0.37^{\mathrm{a}}$ & $22.35 \pm 0.48^{\mathrm{ab}}$ & $35.43 \pm 0.69^{b}$ \\
\hline & Jejunoileum $(\mathrm{U} / \mathrm{g})$ & $30.59 \pm 2.27^{\mathrm{a}}$ & $35.31 \pm 0.71^{\mathrm{ab}}$ & $37.63 \pm 0.66^{\mathrm{ab}}$ & $42.51 \pm 0.55^{\mathrm{h}}$ \\
\hline \multirow{2}{*}{ Total } & Duodenum (U) & $11.63 \pm 0.86^{a}$ & $16.26 \pm 0.24^{b}$ & $19.37 \pm 0.34^{b}$ & $25.35 \pm 0.56$ \\
\hline & Jejunoileum (U) & $13.58 \pm 0.39^{a}$ & $19.90 \pm 0.24^{\mathrm{ab}}$ & $23.20 \pm 0.55^{\mathrm{ab}}$ & $30.23 \pm 0.83^{\mathrm{h}}$ \\
\hline
\end{tabular}

which may be the main reason for low utilization of nutrient (Qi et al., 2010).

Digestive organ indices are the basis of understanding and exploring the physiological mechanisms of feeding, digestion and absorption of birds (Zheng, 1995). Numerous studies have confirmed that food source for birds is the main factor affecting the digestive organs of birds. This study found that, with the level of PER elevated, the weight and digestive organ indices of digestive organs exhibited a certain trend. Feed intake of the birds should first meet the needs of energy (Nahashon et al., 2005), and the feedstuff intake should be adjusted according to the dietary metabolizable energy (ME) level; if the dietary ME level is changed, the feed intake would change accordingly, and also the nutrient intake will changed, thereby affecting the development and physiological state of the body organs (Mcdonald et al., 2002).

The pancreas is the most important digestive gland of animals, and most of the small intestine protease come from pancreas; Digestive enzymes activities in pancreas are highest and much higher than other parts of the gut (Yang and Wang, 2007). This study found that the relative activity of trypsin and chymotrypsin in various digestive organs initially increased and then decreased, and reached the maximum value in PERII. When the intestinal tract moved backward, the activity of trypsin and chymotrypsin gradually decreased, exhibiting the trend pancreas $>$ duodenum $>$ jejunoileum. Proteases play an important role in protein hydrolysis process. The activity of protein digestive enzymes in digestive organs followed the enzyme-substrate doctrine. In the present study, the dietary protein level of each PER group was same, but dietary energy differences lead to different amount of protein in take, resulting in digestive enzymes activities differences. For each treatment group, the digestive enzymes activities in the digestive organs of $L$. luteal were consistent with the utilization rate of protein in feedstuff, which reflected the unity of animal structure and function.

Lipids are the most important energy substance of animals. Under physiological conditions, lipids contain 2.25 times more energy than either carbohydrates or protein. Enzymes involved in fat digestion in birds are mainly the gastric lipase secreted by glandular stomach wall and intestinal lipase secreted by duodenum (Wang et al., 2010). In the present study, the relative activity of lipase in pancreas, duodenum and jejunoileum gradually decreased when the PER level was elevated, which might be related with the gradual decreased level of dietary fat. This study also found that as the level of dietary fat gradually decreased, the utilization rate of dietary fat gradually improved, and the reason might be the higher fat content and lower lipase activity which easily lead to fat malabsorption and diarrhea (Zheng and $\mathrm{Li}$ 2005). Therefore, in the preparation of feedstuff for 
caged birds, besides considering the dietary fat to balance the PER level, the utilization and digestion rate is another key factor to be considered.

Carbohydrates are the most important energy source for the birds. As omnivorous bird, the $L$. luteal eats a wide range of things, including insects, seeds, grain, grasses (Guo et al., 2009); Carbohydrates include small molecules of sugar, starch, cellulose, etc. In this study, the amount of carbohydrates in the diets of $L$. luteal was adjusted by adjusting the amount of cereal seeds and soybean meal. With the intestinal tract moving backward, carbohydrate enzymes activities gradually increased. Numerous studies have confirmed that most of the enzymes activities are affected by its environmental $\mathrm{pH}$. The optimum $\mathrm{pH}$ of various enzymes are sometimes different due to different substrate type, substrate concentration and buffer composition (Shen et al., 1990). It was found that the $\mathrm{pH}$ of the intestinal content was 5.2 to 7.5 , the approximate value was 6.5 (NAS, 1983). Many domestic and foreign research results also showed that the optimum $\mathrm{pH}$ value of the carbohydrate enzymes should be in the weakly alkaline range or neutral to slightly alkaline range. This study also found that the cellulase activities and total enzyme activities in duodenum and jejunoileum of $L$. luteal were much higher, which theoretically explain that the omnivorous birds possessed a strong ability to digest feedstuff containing high fiber levels (Song et al., 2000). Therefore, an appropriate amount of grain seeds in feedstuff of $L$. luteal could not only promote the intestinal health, but also save costs, and improved economic efficiency.

In the preparation of the feedstuff for birds, in addition to considering the appropriate $\mathrm{CP} / \mathrm{ME}$ ratio, calcium to phosphorus ratio is another very important factor to be considered. In this study, based on the calcium and phosphorus requirement for growth of quail, the diets was prepared according to the ratio of calcium to phosphorus as 1.5:1. The results show that, for the $L$. luteal, the calcium utilization rate was only about $20 \%$, and the utilization rate of phosphorus was up to $70 \%$. Evidence showed that inappropriate ratio of calcium to phosphorus affected the absorption of calcium; Reducing the ratio of calcium to phosphorus could improve the utilization of phosphorus (John, 1998). This suggests that the ratio of calcium to phosphorus should be improved to accelerate the utilization of calcium in L. luteal, which needs to be further studied. In addition, the cellulase activity in intestinal tract of $L$. luteal reflected the number of intestinal flora; Some gastrointestinal bacteria (i.e. Bacillus) could secrete phytase, to promote the release of phytate, thereby increasing the total phosphorus utilization efficiency.

\section{Conclusion}

Different PER feedstuff could affect the PER, ADFI, the apparent utilization rate of energy, fat and crude protein, development of digestive organs and digestive enzymes in L. luteal. With comprehensive consideration of the experimental results, the formulations of PER II treatment was suitable for the nutrition needs of captive $L$. luteal.

\section{ACKNOWLEDGEMENTS}

This research was financially supported by Startup Project of Doctor Scientific Research (project number 08B081) from China West Normal University, Key Research Project of the Sichuan Province Education Department of China (project number 11ZA032) and Sichuan Province Outstanding Young Persons of Academic Technology Leaders Follow-up Plans (project number 2011JQ0056).

\section{REFERENCES}

Chan AAS (2005). Encyclopedia of feedstuff preparation, China Agriculture Press. p. 248.

Fan Z (1997). Birds listed in Appendix II by the Convention on International Trade in Endangered Species of Wild Fauna and Flora (CITES). China For. 12:41.

Guo WC, Zhou SR, Bao XF (2009). Feeding and management of Leiothrix luteal. Spec. Econ. Anim. Plant p. 11.

John G (1998). Reduced calcium: phosphorous ratio may increase phosphorous utilization. Feedstuffs 5:12-13.

Liu XH, Long GZ (1989). A preliminary study on the ecology of the redbilled leiothrix. Chin. Wildl. 6:58-62.

Ma JN, Phillips J, He FQ (2000). A field guide to the birds of China. Changsha: Hunan Education Publishing House, p. 414

Ma Q, Xiao WF, Su HL (2010). The preliminary study on breeding habit of Leiothrix lutea at Xingshan County, Hubei. Chin. J. Zool. 45(2):4651

McDonald P, Edwards RA, Greenhalg FD (2002). Animal Nutrition (6th Edition). New Jersey: Prentice Hall, pp. 464-480.

Nahashon SN, Adef ON, Amenyenu A (2005). Effects of dietary metabolizable energy and crude protein concentrations on growth performance and carcass characteristics of French guinea broiler. Poult. Sci. 84(2):337-344

NAS (National Academy of Science) (1983). Nutrient requirement of warmwater fish and shellfish. Washington, DC: National Academy Press, pp. 39-40.

Qi SF, Yuan SB, Yuan H (2010). Morphological observation on the digestive system of Leiothrix lutea. Sichuan J. Zool. 29(4):601-604.

Shen T, Wang JY (1990). Biochemistry. Higher Education Press. $2^{\text {nd }}$ edition. pp. 231-251.

Song DJ (2000). Comparing the utilization of energy, amino acids and fiber in feedstuff of chickens and ducks and the assessment of true metabolizable energy in fiber. Sichuan Agricultural University. pp. 5158.

Stellmacher (1992). Methods for measuring enzyme activities. Beijing: China Light Industry Press. pp. 231-251.

Sun JH (1996). The cage rearing technology of Leiothrix luteal. China Poult. 5:37-38.

Wang CZ, Wang T (2006). Experiment Instruction of Feed science. China Agricultural Press. pp. 41-45.

Wang J, Zang SM, Yuan N (2010). Comparison of main digestive enzymes between Taihang layer and Hy-Line layer in growth period. Acta Agriculturae Boreali-occidentalis Sinica. 19(6):38-43.

Yang HM, Wang ZY (2007). Effects of different diets on the digestive enzymes activities. Jiangsu Agric. Sci. (6):199-201.

Zheng GM (1995). Ornithology. BeiJing: Beijing Normal University Press. pp. 347-353.

Zheng GM (2005). A checklist on the classification and distribution of the birds of China. Beijing: Science Press pp. 270-271.

Zheng T, Li A (2005). Progress in poultry gastrointestinal enzyme secretion and activity influencing factors. Anim. Husb. Vet. Med. $37(6): 59-62$. 